\section{No growth for British science}

SIR - Terence Kealey's rosy-hued vision of the growth of British science (Nature 350, 370 ; 1991) defies belief. I must draw attention to the gross and chronic inadequacy of the public monies available through the socalled dual-support system for funding the indirect (but real) cost of research whose direct costs are provided by research councils and UK charities. The facts are as follows.

(1) The Department of Education and Science (DES), the Universities Funding Council (UFC, formerly the University Grants Committee, UGC) and the Committee of Vice-Chancellors and Principals (CVCP) have all urged universities to recover the full costs of all research undertaken, rather than drive themselves into insolvency. In particular, we were urged to adopt the Hanham formula which shows that the typical level of indirect cost is 60 per cent of the direct costs for any given project. (2) For research where the direct costs have been borne by research councils and UK charities, the indirect costs, under the dualsupport system, have been provided as DR by the UGC/UFC. (DR is UFC research money distributed to universities according to their research grant income from the research councils and charities.)

(3) However, compared with the 60 per cent required, DR has never exceeded 31.5 per cent and has declined steadily to 23 per cent. This comparison between 60 per cent and 23 per cent is unaffected by international comparisons, gross domestic product, inflation or anything else. It represents chronic failure of the dual-support system to do what it is supposed to do. In 1990-91, the shortfall across the system is $£ 160$ million.

(4) Recent case analyses conducted by the research councils and several universities (including University College London) confirm the 'Hanham 60 per cent' and will no doubt influence the sum sought by the Advisory Board for the Research Councils from the UFC to meet the proposed transfer of responsibility.

(5) The shortfall, though, is not a result of that transfer, but is, rather, the result of gross underfunding of the UFC by the DES and the Treasury.

\section{H. ROBERTS} (Provost)

\section{University College London,}

Gower Street, London WC1E 6BT, UK

SIR - We have carried out a survey of the contribution of laboratories from various countries to publications in Nature over the past 25 years. Between seven and ten issues of Nature were taken randomly for each year examined, and studies were carried out at five-yearly intervals from 1965 to 1990 . For Articles and Letters, the number of publications in which a particular country was represented in terms of authorship was recorded. Thus, papers involving authorship from two or more laboratories in the same country scored only one for that country, and authorship from more than one country scored one for each country.

The figure shows the trends in relative representation of different countries to authorship of Nature Articles and Letters since 1965. A very clear decline is seen in the United Kingdom contribution: in 1965, 34.6 per cent of authorships were from the United

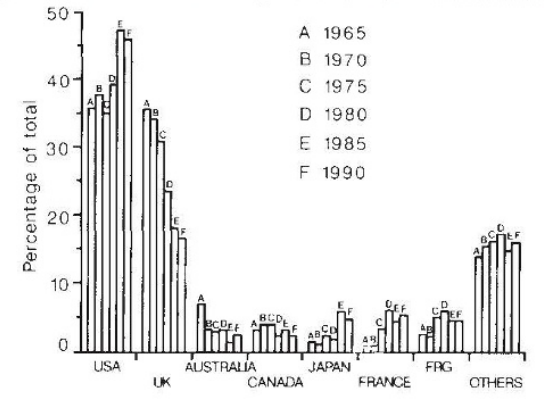

\section{Vitamins and IQ}

SIR - There has been a lively discussion in Nature $(350,2$ \& 5; 1991) of a report attributed to "Californian research" that a vitamin-mineral supplement will increase IQ in children. The editor (page 3) speculates that the effect would put schoolteachers out of work, but the need for them is increased by eager and more intelligent pupils.

Why did the story produce a complete lack of interest in California? One possible explanation is that Californians consume so many vitamins that they are too intelligent to believe it. At the same time, we feel a certain unkind satisfaction that the United Kingdom, where criticisms of Californians' exuberance are complacently aired, should have been so easily hoodwinked. Peter Aldhous (page 5) calls for peer reviews. Perhaps the real problem is one of gullibility.

One obvious question was not raised in Nature. The product was a vitamin-mineral supplement containing ten minerals. Why is the alleged effect attributed to vitamins rather than to minerals? What about signal transduction by calcium?

Division of Biophysics, THOMAS H. JUKES University of California, Berkeley, California 94720, USA

\section{Patent confusion}

SIR - F. W. Cousins' comments (Nature 340, 184; 1991) on the "withdrawn" British patent applications for zidovudine (formerly known as AZT) indicate a lack of knowledge of the current patent system. It is fairly common practice to establish a formal priority date by filing a basic application in the United Kingdom, then on foreign filing 12 months later to file an application in Europe designating the countries in which cover is
Kingdom, whereas the value fell to 16.7 per cent in 1990. This fall in UK contribution was compensated for by a rise in US authorships (34.6 per cent in 1965 to 45.8 per cent in 1990) as well as by a rise in authorship representation from other countries, in particular Japan, France and Germany.

Assuming that Nature accepts articles solely on the basis of scientific merit, we suggest that these data provide clear evidence for a decline in international competitiveness of British scientific research. With the continuing fall in government support for basic research in the United Kingdom, it is pertinent to ask whether this decline will continue.

Biology Department,

Frank Ashall

Imperial College, London SW7 2BB, UK

Department of Biochemistry \&

Alison M. Goate

Molecular Genetics,

St Mary's Hospital Medical School, London W2 1PG, UK

desired and claiming priority from the British application. That itself is generally not pursued any further by the applicant, in due course is "deemed abandoned" by the British Patent Office and five years after first filing the Patent Office file is destroyed.

In the case of zidovudine, this has now occurred with basic British applications which were filed in 1985 and 1986 and to which Cousins referred. The European patent, which Cousins does not cite, is 000196185 .

The German Offenlegungsgeschrift 3608606 was similarly abandoned, its claims also being covered by the European patent. MichaEL P. JACKSON

The Wellcome Foundation Ltd,

Langley Court,

South Eden Park Road,

Beckenham, Kent BR3 3BS, UK

\section{Too many noughts}

SIR - I would like to call your attention to an error in "Bush asks for 13 per cent extra for science" (Nature 349, 443; 1990). You state that the Human Genome Project is in line for a \$334 million increase. This is clearly an editorial slip, because that sum far exceeds the combined genome budgets of both the National Institutes of Health (NIH) and the Department of Energy (EOE). As your table shows, the increase requested for the combined NIH and DOE genome programmes is in fact $\$ 35$ million. Of this NIH have requested an increase of $\$ 23$ million.

The uninformed reader could get a false and exaggerated impression about the size of the US budget for genome research from your article, creating unnecessary concern.

James D. Watson

(Director, National Center for Human Genome Research)

National Institutes of Health,

Bethesda, Maryland 20892, USA 